\title{
Efeitos colaterais da meritocracia na educação: a rede municipal de educação de Foz do Iguaçu e o IDEB
}

\author{
Side effects of meritocracy in education: the network hall of Foz do Iguaçu \\ education and IDEB \\ Los efectos secundarios del sistema basado em el mérito proprio em la \\ educación: la red municipal de la educación de Foz do Iguaçu y el IDEB
}

\section{SILVIO BENITEZ \\ SILVANA APARECIDA DE SOUZA}

\begin{abstract}
Resumo: O objetivo deste texto é fazer uma reflexão sobre os efeitos colaterais da implantação da meritocracia nas escolas municipais de Foz do Iguaçu. Como fonte utilizou-se o conteúdo de matérias jornalísticas publicadas na imprensa local, assim como os relatórios de uma Comissão Especial do IDEB criada pela Câmara Municipal. Conclui-se que as categorias delimitadas pela análise de Ravitch se fazem presentes também em Foz do Iguaçu, demonstrando que os sistemas de avaliação de larga escala provocam efeitos similares aos estudos da autora.
\end{abstract}

Palavras-chave: Educação; IDEB; Meritocracia.

Abstract: The objective of this text is to do a reflection on the side effects of the implantation of the meritocracy in the municipal schools of Iguassu Falls. As sources, the content of journalist matter was used published in the local press, as well as the reports of a Special Commission of IDEB created by th Citi Hall. It is ended that the categories delimited by the analysis of Ravitch are done presents also in Iguassu Falls, demonstrating that the evaluation systems of wide climb provoke similar effects tho the author's studies.

Keywords: : Education; IDEB; meritocracy.

Resumen: El propósito de este trabajo es reflexionar acerca de los efectos secundarios de la aplicación de la meritocracia en las escuelas públicas en Foz do Iguaçu. Como fuentes, se utilizó el contenido de los artículos periodísticos publicados en la prensa local, así como los informes de una la Comisión Especial IDEB establecidos por la Cámara Municipal. Conclui que las categorías definidas por el análisis de Ravitch están también presentes en Foz do Iguaçu lo que demuestra que los sistemas de evaluación a gran escala causan efectos similares a los estudios de la autora.

Palabras clave: Educación; IDEB; Meritocracia. 


\section{INTRODUÇÃO}

O município de Foz do Iguaçu possuía, no ano de 2011, um total de 2.934 servidores municipais, entre professores, supervisores, diretores, estagiários e funcionários da carreira administrativa e de apoio; destes, 1.212 eram professores. $\mathrm{Na}$ rede do ensino regular, entre Ensino Fundamental e Educação Infantil, matriculados em 85 estabelecimentos de ensino, dos quais 51 escolas de ensino fundamental e 34 centros de educação infantil, possuía 19.585 alunos. A taxa de aprovação do ensino fundamental foi, em 2011 , de $97,84 \%$ e a de reprovação, de 2,14\%. (FOZ DO IGUAÇU, 2011).

A implantação da meritocracia ${ }^{1}$ na rede municipal de Foz do Iguaçu consistiu em estabelecer metas de elevação do índice do IDEB $^{2}$, sendo possível às escolas atingirem duas metas e obterem duas premiações: o $14^{\circ}$ salário e $15^{\circ}$ salário.

O governo municipal implantou essa política pública na educação através do Decreto $\mathrm{n}^{\circ} 21.404$, de 22 de junho de 2012, que regulamenta o pagamento do $14^{\circ}$ salário, em compensação pelas notas da avaliação do IDEB do ano de 2011, cujo resultado foi divulgado em 2012. Esse decreto estabeleceu a meta que cada escola deveria atingir para que seus trabalhadores recebessem o $14^{\circ}$ salário. $\mathrm{O}$ artigo $1^{\circ}$ explicita claramente os objetivos dessa política e define quem serão os beneficiados com a nota da escola:

\footnotetext{
Regulamentar e disciplinar, no âmbito da Secretaria Municipal da Educação, o Acordo Metas do Programa Gestão para Resultados, a serem atingidas e a forma de pagamento do Prêmio por Desempenho - PD - previsto na Lei no 3.961, de 10 de abril de 2012.

Parágrafo Único - Farão jus ao Prêmio de que trata este Decreto os seguintes cargos: Ajudante de Serviços Gerais, Assistente Administrativo, Atendente de Creche, Educador, Educador Infantil, Instrutor de Ensino, Merendeiro, Nutricionista, Professor e Secretário de Escola. (FOZ DO IGUAÇU, 2012)
}

Ainda conforme o art. $4^{\circ}$ do Decreto $n^{\circ}$ 21.404/2012: "se o índice alcançado pela escola for inferior ao proposto em um décimo será efetuado o

\footnotetext{
1 indivíduo e sua recompensa por meio do seu desempenho, rejeitando toda e qualquer forma de privilégio hereditário ou corporativo. Ao basear-se no mérito para reconhecer e remunerar de forma compatível com a entrega dos resultados, a gestão de pessoas busca conciliar e satisfazer as expectativas das pessoas e das organizações. (CHAVES, 2012. p. 102)

2 O Índice de Desenvolvimento da Educação Básica (IDEB) foi criado pelo Instituto Nacional de Estudos e Pesquisas Educacionais Anísio Teixeira (Inep) em 2007 e é um indicador que reúne dois conceitos igualmente importantes para a qualidade da educação: fluxo escolar e médio de desempenho nas avaliações em larga escala realizadas pelo Inep. (BRASIL, 2011)
} 
pagamento em $80 \%$ (oitenta por cento) da remuneração". Além do $14^{\circ}$ salário, o Decreto 21.404/2012 também prevê o pagamento do $15^{\circ}$ salário aos trabalhadores das escolas que atingirem as metas estabelecida. (FOZ DO IGUAÇU, 2012)

$\mathrm{O}$ trabalho direcionado para a conquista de melhores índices no ranking nacional do IDEB, realizado pela Prefeitura Municipal de Foz do Iguaçu através da Secretaria Municipal da Educação, e o incentivo através da meritocracia levaram as escolas municipais de Foz do Iguaçu a elevarem rapidamente e em percentual bem acima dos níveis nacionais, os índices do IDEB no ano de 2011 e a obterem as melhores colocações no ranking nacional e estadual.

De acordo com o resultado do IDEB 2011, divulgado pelo Inep em 2012, a Escola Municipal Santa Rita de Cássia obteve o primeiro lugar nacional, empatando com a Escola Carmelita Dramis de Itaú de Minas, localizada no interior de Minas Gerais, com a média 8,6. Entre as dez escolas do Brasil que melhor pontuaram, três são de Foz do Iguaçu: a Escola Santa Rita de Cássia, com índice 8,6, a Escola Municipal Papa João Paulo I, com índice 8,3, e a Escola Municipal Benedicto João Cordeiro, com índice 8,2. (BRASIL, 2012a). Segundo o Jornal Gazeta do Povo (2012), entre as vinte escolas do Paraná mais bem colocadas no ranqueamento, dez são escolas iguaçuenses.

Sempre tomando os dados do IDEB de 2011, é importante considerar a evolução da média do município de Foz do Iguaçu e a meta projetada, conforme resultado divulgado no site do INEP “IDEB Resultados e Metas” em 2005 é 4,2, em 2007,é 4,8 e a meta 4,3; em 2009 é 6,2 e a meta 4,3; em 2011é 7,0 e a meta 5,0. (BRASIL, 2012b)

Considerando que a meta estabelecida pelo Inep para o ano de 2021 é 6,3 (que toma como parâmetro a nota das escolas da Europa), que a média estadual é 5,2 e a média nacional é 5,0 (BRASIL, 2012b) e, ainda, que o menor índice das escolas municipais é 6,2 (BRASIL, 2012a), conclui-se que todas as escolas municipais de Foz do Iguaçu já superaram a meta estabelecida pelo MEC para o ano de 2021. 


\section{EFEITOS COLATERAIS E AS CATEGORIAS DE ANÁLISE DE RAVITCH}

O termo "efeitos colaterais" é uma metáfora médica por comparar a sociedade com o corpo humano ${ }^{3}$. Na presente pesquisa, o sentido figurado é utilizado como forma de dar compreensão e ressaltar as consequencias, muitas vezes indesejadas, da aplicação do "remédio" para a educação. O termo foi utilizado pelo ex-presidente do INEP, Reynaldo Fernandes ${ }^{4}$, em uma entrevista para a Revista Educação, para explicar as consequencias da responsabilização sobre resultados:

Quando se cria um sistema de avaliação e passa a haver responsabilização pelos resultados, os gestores vão se preocupar com as notas e as metas. Qual é a defesa desse sistema: se existe um mecanismo para atribuir responsabilidades, os gestores vão melhorar o ensino. Quais são as críticas? Eles podem tentar falsear as notas, excluir os alunos mais fracos. Nos Estados Unidos, isso aconteceu. Esses argumentos não têm como ser revidados. Mas não se pode deixar de dar um "remédio" para a educação por causa dos efeitos colaterais que ele pode causar. Temos de ver se é melhor ou pior para a qualidade da educação. Acho que é melhor. Os efeitos colaterais devem ser combatidos. Quando a primeira-ministra Margareth Thatcher fez a reforma educacional, diziam que era uma visão de direita. Quando o Tony Blair se tornou primeiro-ministro, acreditavam que ele suspenderia a reforma. Mas ele a reforçou e combateu os "efeitos colaterais". Criou um programa de combate à exclusão dos piores estudantes, e as expulsões de alunos diminuíram absurdamente. (FERNANDES, 2007, s/p)

A implantação da meritocracia nas escolas municipais de Foz do Iguaçu, que,por um lado,propiciou a elevação repentina do índice do IDEB do município, por outro causou "efeitos colaterais", que colocam em dúvida se essa elevação de índice vem realmente acompanhada da elevação da qualidade da educação, como propõe o Ministério da Educação. Segundo Diane Ravitch ${ }^{5}(2011)$, esses “efeitos

3 A metáfora (do grego metaphorá = transporte) é uma comparação abreviada. Se eu digo que Paulo é valente como um leão, tenho uma comparação. Se digo, entretanto, que Paulo é um leão, abreviando a comparação pela eliminação de valente como, tenho uma metáfora. Daí a ideia de transporte, do sentido próprio para o sentido figurado.[...] Metáfora Médica é de grande poder argumentativo, pois tem apelo universal. Ela compara a sociedade ao corpo humano e nos fala de lares, remédios e curas. Dessa maneira, ganha uma importância considerável dizer que o governo criou a quimioterapia do real para extirpar o câncer da inflação. (ABREU, 2005. p. 50-51)

4 Economista da Universidade de São Paulo (USP) Ribeirão Preto, hoje membro do Conselho Nacional de Educação.

5 Diane Ravitch foi subsecretária da educação do ex presidente dos Estados Unidos da América George Bush, quando implantou a abordagem da responsabilização e meritocracia, que abandonou depois de vivenciar as consequencias dessa política, que, no caso,ela mesma ajudou a implementar naquele país. Hoje é uma das maiores ativistas contra este tipo de enfoque para a educação. 
colaterais" eram previsíveis, uma vez que os profissionais envolvidos na educação são pressionados, antes de tudo, a apresentar melhores índices:

\begin{abstract}
Quanto mais um indicador social quantitativo é utilizado para fins sociais de tomada de decisão, mais sujeito ele estará à pressão de corrupção e mais apto ele estará a distorcer e corromper os processos sociais que se pretende (sic) monitorar. [...] As mudanças induzidas pelas pressões da responsabilização corrompem o próprio propósito da escolarização, causando a focalização dos profissionais na mensuração ao invés de nos objetivos da educação. (RAVITCH, 2011, p. 49).
\end{abstract}

Esses "efeitos colaterais"dos testes de larga escala ocorrem em função da pressão que os envolvidos recebem para elevar os escores e,até mesmo, como forma de evitar humilhação. Segundo Ravitch (2011, p. 253-254) "quando os testes são o método primário de avaliação e responsabilização, todos se sentem pressionados a elevar os escores, por bem ou por mal. Alguns irão trapacear para obter uma recompensa ou evitar a humilhação".

Com base na psicologia behaviorista de John Watson (estímulo-resposta), explicam-se os "efeitos colaterais" da seguinte forma: "nós somos o que fazemos, e o que nós fazemos é o que o meio nos faz fazer. Dessa forma, os indivíduos não são pessoalmente responsáveis pelos seus atos, dado que são produto do meio em que vivem."(LOPES; NICOLAU 2013, s \p). No caso da rede municipal de educação do município de Foz do Iguaçu, esse estímulo se apresenta em forma dos $14^{\circ}$ e $15^{\circ}$ salários, seguindo a lógica de mercado, no interior da qual o comportamento das pessoas nas organizações é motivado por recompensas financeiras.

Os "efeitos colaterais" da meritocracia na educação foram objeto de denúncias na Câmara Municipal de Foz do Iguaçu, que criou uma Comissão Especial do IDEB, pela Portaria da Presidência no 072/2013, com a finalidade de promover o estudo e a tomada de posição acerca da adequação do índice de desenvolvimento da educação básica (Ideb) como método de avaliação da educação pública prestada no município de Foz do Iguaçu. Fizeram parte dessa comissão os vereadores DiltoVitorassi, Nilton Bobato e Fernando Duso. Foram ouvidas as professoras Ivone Elizabeth Nieradka, Márcia Bengos Bertagna, Maria Justina da Silva, Dinorá Francisca de Moraes Rocha, Marli Salete da Costa Silva, Maria Bernadete Sidor, Shirlei Ormenese de Carvalho, Ivone Aparecida Müller e Silvana Aparecida de Souza.

Como resultado dos levantamentos efetuados, o relatório oficial da Comissão do IDEB concluiu que as denúncias são inconsistentes por falta de provas. No entanto, o presidente da comissão discorda dessa conclusão e continua a afirmar que "a avaliação do IDEB apresenta incoerência e vulnerabilidade;no 
entanto, devido a interesses políticos, inclusive de membros da comissão, não foi constatado(sic) nenhuma fraude no processo" (O IGUASSU, 2013, p. 6).

Em função da divergência com o resultado do relatório oficial da Comissão Especial do IDEB, da Câmara dos Vereadores de Foz do Iguaçu, o presidente e propositor daquela comissão, o vereador DiltoVitorassi, elaborou um relatório próprio, em contraposição ao documento elaborado pelo relator da comissão, o vereador Nilton Bobato, membro da coligação e do governo do exprefeito da cidade, que implantou a meritocracia como forma de remuneração dos professores da rede municipal de Foz do Iguaçu.

Em seu relatório "paralelo", o vereador Vitorassi apresenta relatos importantes de professores e conclusões relevantes. Esse relatório paralelo, apesar de ter sido encaminhado a diversos órgãos para ciência, foi arquivado juntamente como relatório oficial. (O IGUASSU, 2013, p. 6).

Passamos, a seguir, a relacionar, um a um, os efeitos colaterais da política de avaliação em larga escala e de meritocracia, definidos por Ravitch, procurando relacioná-los com indícios dos efeitos causados na educação municipal de Foz do Iguaçu, pela política meritocrática de elevação do IDEB:

Elevação repentina dos escores - Segundo dados do Inep, o índice do IDEB de Foz do Iguaçu elevou-se de 4,2 em 2005 para 7,0 em 2011(BRASIL, 2012b). Esse aumento repentino é questionado pela professora Dinorá Francisca de Moraes Rocha em seu depoimento à Comissão Especial do IDEB:

A gente vê que o índice saiu de 5,0 para 7,0 em cinco ou seis anos, isso é irreal, a gente trabalha na educação há vinte e oito anos e nunca aconteceu isso, o índice passou em pouco tempo para uma nota muito alta. (A FRONTEIRA, 2013c, s \p)

E, ainda, do Relatório do vereador Vitorassi, Presidente da Comissão Especial do IDEB consta que:

Em relação a esse tipo de "avanço" no IDEB não só localmente, demasiadamente elevado para tão pouco tempo, diversas controvérsias foram levantadas, inclusive sobre o fato de índices obtidos talvez não corresponderem necessariamente a um aumento real dos fatores de desempenho dos alunos e aumento das taxas de aprovação. (O IGUASSU, 2013, p. 8)

O estudo de Camargo, Pinto e Guimarães (2008, p. 831) constatou que:

Mais da metade (668 municípios) apresentaram uma variação positiva do IDEB na comparação igual ou maior que 30\% entre 2005 e 2007; 287 (23\%) tiveram uma variação igual ou maior a $40 \%$; $167(13,5 \%)$ viram seu IDEB crescer $50 \%$ ou mais; 18 municípios tiveram o índice dobrado e 4 triplicados. 
E ainda, sobre esses surpreendentes resultados positivos,

Qualquer pesquisador ou gestor educacional sabe que as redes de ensino não apresentam saltos dessa natureza em prazo tão curto, os estudos na área mostram também que as notas dos alunos estão muito vinculadas ao nível socioeconômico das famílias e, portanto, não sofrem grandes variações em intervalo curto de tempo. (CAMARGO; PINTO; GUIMARÃES, 2008, p. 832)

Liberação de fluxo - Segundo dados fornecidos pela Secretaria Municipal da Educação, Divisão de Documentação e Legislação Escolar de Foz do Iguaçu, no ano de 2005, o índice de aprovação era de 84,9\% e o de reprovação, de15,1\%; em 2011, após a implantação da meritocracia na educação, esses índices se elevaram para 97,84\% de aprovação e 2,16\% de reprovação.Através do Gráfico 2, é possível perceber,ainda,que o índice de reprovação é menor em anos de avaliação do IDEB (anos ímpares), ou seja, as retenções de alunos ocorrem, em maior proporção, em anos em que não ocorre a avaliação de larga escala.(FOZ DO IGUAÇU, 2011).

\section{GRÁFICO 1- Índice de aprovação e reprovação nas escolas municipais de Foz do Iguaçu no período de 2005 a 2011.}

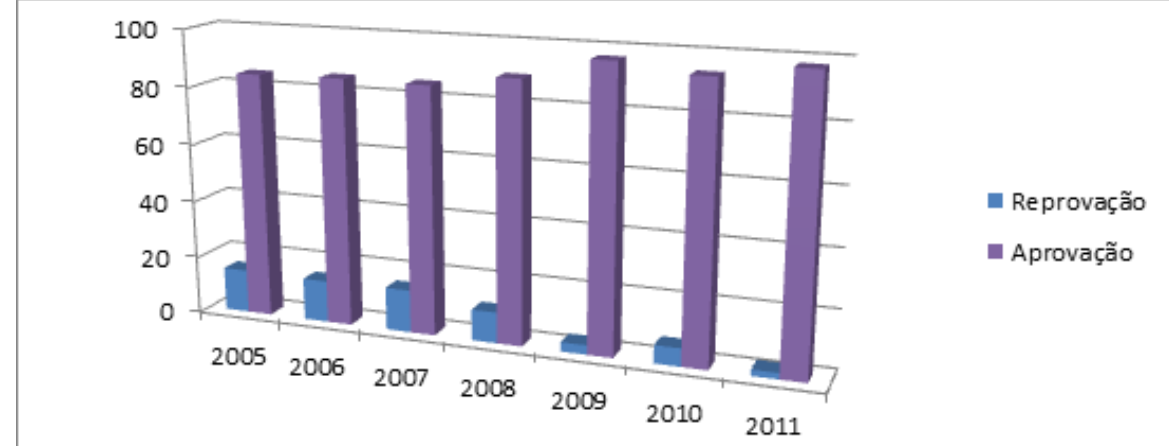

FONTE: Elaboração do Autor com base em dados da Secretaria Municipal da Educação/ Divisão de Documentação e Legislação Escolar/ Estatística do Resultado Final.(FOZ DO IGUAÇU, 2011)

Considerando que o índice de aprovação é um dos componentes da avaliação do IDEB, e, conforme o depoimento da professora Dinorá Francisca de Moraes Rocha à Comissão Especial do IDEB, em ano de avaliação de tal índice, os professores são forçados a aprovar alunos:

O que a gente questiona, em ano de IDEB, é a forma que é vista o índice de reprovação, que é um dos critérios do IDEB. No ano de IDEB há uma pressão muito grande para não reprovar, é o mínimo do mínimo do mínimo, e isso faz 
com que os professores se frustrem porque ela batalha, batalha e batalha e ainda existe na sala de aula alunos [que]não conseguem superar seus limites, são alunos com desestruturação familiar, dificuldade de aprendizagem, portadores de alguns transtornos e eles não conseguem ultrapassar e a gente vê que até mesmo esses alunos são forçados a serem aprovados. (A FRONTEIRA, 2013c, s/p)

Conforme depoimento, na Comissão Especial do IDEB de Foz do Iguaçu, da chefe do Núcleo Regional da Educação Professora Ivone Muller, o prêmio em dinheiro para toda a escola foi uma forma de pressão para que os professores aprovassem os alunos:

Se eu fosse uma professora que tivesse que reprovar um aluno e essa reprovação comprometesse as metas para o IDEB isso resultasse na perda do prêmio em dinheiro para todos na escola, eu me sentiria pressionada a passar o aluno. (O IGUASSU, 2013, p.17)

Segundo o relatório do presidente da Comissão Especial do IDEB, vereador DiltoVitorassi, muitas aprovações foram forçadas através de Conselho de Classe:

Segundo apurado pelo jornal O IGUASSU (ed. 61) junto aos professores das escolas municipais ouvidos por aquele periódico local, muitas aprovações de alunos, reprovados por professores da Rede Municipal, foram feitas por "Conselhos de Classe" para que essas reprovações não interferissem no resultado do IDEB.(O IGUASSU, 2013,p. 17)

Para o professor Doutor Luiz Carlos de Freitas (2007), a liberação de fluxo não significa aumento do desempenho do aluno:

Somos contra a reprovação, mas não podemos fazer disso o foco da atuação das políticas públicas, inclusive porque nem toda reprovação se dá por causas pedagógicas. Combater a reprovação é apenas uma parte da solução. A questão de fundo é ensinar a todos e a cada um. A redução dos índices de reprovação é necessária, mas não é suficiente. Mais ainda, dada a composição do IDEB, ele poderá estimular no curto prazo a liberação do fluxo para reduzir a reprovação,regularizando o tempo de permanência do aluno na escola e aumentando o valor do IDEB, sem que isso necessariamente signifique aumento do desempenho do aluno.(FREITAS, 2007, p.979-980)

Precarização do currículo escolar - Considerando que as áreas do conhecimento que são cobradas na Prova Brasil são somente Matemática e Língua Portuguesa, o professor,em geral, é pressionado a priorizar essas duas áreas no seu trabalho cotidiano de ensino. Dessa forma, ocorre o escamoteamento e, consequentemente, a precarização do currículo, pois disciplinas como História, Geografia, Ciências e Educação Física, apesar de serem fundamentais para a 
formação do estudante, acabam sendo relegadas a segundo plano. Prova disso é o depoimento da professora Marli, na Comissão Especial do IDEB, quando afirma: "se o nosso IDEB tivesse sido real, não teríamos reprovação no $6^{\circ}$ ano porque o que se aprende não se esquece" (A FRONTEIRA, 2013b) e, ainda, o depoimento da Professora Ivone Muller, também é esclarecedor nesse sentido, quando afirma: "Recebi alunos que não tinham condições de receber eles nessa série devido ao pouco conhecimento" (O IGUASSU, 2013, p. 11).

O Relatório do presidente da Comissão Especial do IDEB denuncia o não cumprimento da LDB, com relação à oferta da disciplina de Educação Física:

O Preço do IDEB em Foz do Iguaçu - Precisamos acabar com o "silêncio ensurdecedor" sobre o "custo do IDEB" neste município, onde sequer é cumprido o disposto na Lei de Diretrizes e Bases da Educação (LDB) e a própria Legislação Municipal que determinam a implantação da Educação Física nas escolas municipais, atividade tão importante para o desenvolvimento motor e cognitivo, dentre outros benefícios, que afetam diretamente o desempenho escolar do aluno. (O IGUASSU, 2013, p. 18)

Para Freitas (2007), essa situação possui um agravante, que é o ocultamento da má qualidade da educação:

Há de se considerar ainda que somente língua portuguesa e matemática são medidas nos testes. Mas a escola é mais que isso. Há uma discussão a ser feita, ainda: que tipo de escolarização está sendo oferecido às crianças? O que estão medindo os testes nas avaliações nacionais?Em segundo lugar, há risco de ocultação da má qualidade ao se lidar com a proporção de aprovados na fórmula do IDEB. Como já dissemos, aumento de aprovados não é o mesmo que aumento da aprendizagem.”(FREITAS,2007, p. 981)

A precarização do currículo escolar distorce os objetivos da escolarização. Assim, Ravitch (2011, p.183) afirma: “a responsabilização baseada em testes corrompeu a educação, estreitou e distorceu os objetivos da escolarização”. E sobre a responsabilização dos professores pelas áreas do conhecimento ou disciplinas que são cobradas na prova, Ravitch (2011, p. 184) nos diz: "responsabilizando os professores pelos escores nos testes de leitura e matemática, as escolas prestam menos atenção à saúde do estudante, à educação física, ao conhecimento cívico, às artes e a outras atividades enriquecedoras". E sobre a importância dos conhecimentos que não são cobrados na prova, a autora ainda afirma: "o que é testado pode em última análise ser menos importante do que o que não é testado, como a habilidade de um estudante de encontrar explicações alternativas, levantar dúvidas, buscar o conhecimento por conta própria e pensar de forma diferente." (RAVITCH, 2011, p. 252) 
Competição entre escolas públicas - No que diz respeito à forma como a política de ranqueamento acirra a competição entre as escolas, com o objetivo de pressionar, via opinião pública, o alcance de melhores resultados, transformando o IDEB em um instrumento regulatório, Luiz Carlos Freitas afirma:

O IDEB é mais um instrumento regulatório do que um definidor de critérios para uma melhor aplicação dos recursos da União visando alterar indicadores educacionais. O resultado de cada município e de cada estado será (e já está sendo) utilizado para ranquear as redes de ensino, para acirrar a competição e para pressionar, via opinião pública, o alcance de melhores resultados. (FREITAS apud ARAÚJO, 2007, p. 27)

Após a implantação da política de priorização do IDEB na rede municipal de educação de Foz do Iguaçu, passou a haver uma concorrência ou competição entre as escolas. Ilustrativo disso é o fato de que se tem tornado cada vez mais comum as direções das instituições escolares bem ranqueadas no IDEB colocarem faixas na frente da instituição que dirigem, divulgando a colocação daquela escola. A concorrência entre as escolas é descrita com naturalidade pela professora Ivone Nieradka, diretora de uma das três escolas melhores colocadas no ranking do IDEB em Foz do Iguaçu e no Brasil, em seu depoimento na Comissão Especial do IDEB da Câmara dos Vereadores:

Nas escolas de Foz do Iguaçu vieram as provas lacradas, foram levadas à escola por pessoas estranhas a escolas, porque eram de outras escolas e essas pessoas aplicaram as provas. Eu não acredito que elas venham burlar a aplicação da prova porque nós somos concorrentes delas. Eu não facilitaria a vida de uma escola em detrimento da minha. Eu viria a mudar a nota da minha escola e não de outra. Eu não acredito que tenha ocorrido isso. (A FRONTEIRA, 2013a, $s \backslash p$ )

\section{Escolas com alunos de melhores condições socioeconômicas} apresentam melhores resultados - As injustiças do desempenho escolar relacionadas com o nível sócio econômico são denunciadas por Freitas (2007), que demonstra que estas escondem o problema da desigualdade social:

Nossa sociedade produz tamanha desigualdade social que as instituições que nela funcionam, se nenhuma ação contrária for adotada, acabam por traduzir tais desigualdades como princípio e meio de seu funcionamento [...]. Todos concordamos em que isso não é desejável, mas meras políticas de equidade apenas tendem a ocultar o problema central: a desigualdade socioeconômica. Não é sem razão que os melhores desempenhos escolares estão nas camadas com melhor nível socioeconômico. (FREITAS, 2007, p. 969)

Para Pierre Bourdieu eJean Claude Passeron(1975), na obra A Reprodução, 
a escola acaba cometendo uma "violência simbólica" que é a dominação consentida contra alunos de classe social menos favorecida economicamente, uma vez que estes são levados a acreditar que são menos capazes do que os alunos de classe social mais favorecida economicamente, quando, na realidade, esses alunos não tiveram as mesmas oportunidades. Assim, a escola reproduz e legitima a "ordem social":

O sistema escolar cumpre uma função de legitimação cada vez mais necessária à perpetuação da "ordem social" uma vez que a evolução das relações de força entre as classes tende a excluir de modo mais completo a imposição de uma hierarquia fundada na afirmação bruta e brutal das relações de força. (BOURDIEU; PASSERON, 1975, p.311)

As escolas municipais de Foz do Iguaçu que tiveram melhores resultados foram Santa Rita de Cássia, Papa João Paulo I e Benedicto João Cordeiro, que estão localizadas respectivamente nos bairros Vila Pérola, Parque Presidente e Campos do Iguaçu, que são regiões mais próximas ao centro da cidade onde moram grupos sociais de classe média que, notadamente, possuem problemas sociais em menor gravidade do que as escolas que tiveram os piores resultados, localizados na periferia da cidade. Esse fenômeno foi denunciado na Comissão Especial de IDEB da Câmara Municipal de Foz do Iguaçu e consta do Relatório do Presidente dessa Comissão, conforme divulgado no jornal O Iguassu:

Resultado do IDEB usado como "Ranking" entre as escolas e, com isso, colocando num mesmo critério, escolas com perfis de famílias socioeconomicamente privilegiadas com outras de escolas menos favorecidas.(O IGUASSU, 2013, p. 19)

Treinamento para as provas - Para Ravitch (2011), a preparação para os testes é a forma mais comum de burlar o sistema, embora não leve ao aprendizado:

De todas as maneiras de burlar o sistema, a mais comum é a preparação para o teste. A maior parte dos distritos, especialmente os distritos urbanos onde a performance é a mais baixa, incansavelmente realiza atividades preparatórias para os testes. [...] Mas os distritos escolares têm investido centenas de milhões de dólares em programas e materiais de treinamento para ensinar aos estudantes os tipos específicos de questões que vão aparecer nos testes estaduais. Por semana ou até mesmo antes do teste estadual, as crianças são diariamente treinadas em habilidades de realização de testes e em questões similares às que deverão aparecer no teste estadual. A consequencia de toda essa prática é que os estudantes podem ser capazes de passar no teste, mas não conseguem passar em um teste do mesmo assunto para o qual eles não tenham praticado. (RAVITCH, 2011, p. 181)

Em seu depoimento à Comissão Especial do IDEB, a professora Marli 
Salete Silva denunciou que as crianças do $5^{\circ}$ ano do Ensino Fundamental da rede municipal de Foz do Iguaçu são treinadas para a prova em uma rotina levada à exaustão e que, depois, essas mesmas crianças se esquecem do que aprenderam:

\footnotetext{
No quinto ano, houve um treinamento para as crianças e a diferença é que o que você treina você pode esquecer e o que você aprende você não esquece, nunca. Você aprende o treinamento, você aprende como preenche o gabarito ou uma questão, você treina, treina, treina, depois esquece. O IDEB, para se chegar no ponto máximo no quinto ano,deve ser trabalhado desde o pré-escolar e não só no quinto ano. As crianças são levadas a uma rotina muito cansativa, de manhã e de tarde cansa muito. (A FRONTEIRA, 2013b, s $\backslash p$ )
}

Conforme o relatório do presidente da Comissão especial do IDEB, foi realizado "reforço anormal" por não haver continuidade em anos sem IDEB:

Nos depoimentos nesta Comissão Especial, ficaram comprovadas algumas
fragilidades e vulnerabilidades das avaliações do IDEB aplicadas neste município (e
provavelmente em boa parte do restante do país), as quais precisam ser corrigidas.
[...] Reforço, além do normal, para alunos nos anos do IDEB, para que isso
interferisse no resultado, "reforço anormal" esse, que depois não tem continuidade
nos anos em que não há avaliação do IDEB. (O IGUASSU, 2013, p. 19)

Percebe-se que o relatório do presidente da Comissão especial do IDEB demonstra que, de fato, houve reforço além do normal para os alunos em ano de IDEB, o que coincide com o pensamento de Ravitch (2011) e corrobora com a ideia de que a forma mais comum de burlar a avaliação em larga escala é a preparação dos estudantes especificamente para o teste que compõe a nota do IDEB.

\section{CONSIDERAÇÕES FINAIS}

As investigações realizadas na rede municipal de ensino da cidade de Foz do Iguaçu nos confirmam que a implantação da meritocracia na educação causou alguns efeitos colaterais como a elevação repentina dos escores, a liberação de fluxo, a precarização do currículo escolar, a competição entre escolas públicas, escolas com melhores condições socioeconômicas apresentam melhores resultados e treinamento para as provas.

Há de se considerar, portanto, que os índice do IDEB das escolas públicas de Foz do Iguaçu, da forma como se apresenta, não são confiáveis uma vez que não refletem a realidade das escolas avaliadas, sendo assim a avaliação do IDEB vem contra o objetivo a que se propõe inicialmente que é a melhoria na qualidade da educação, e ainda, vem acompanhado de objetivos ideopolíticos subliminares que são a responsabilização, a meritocracia e a privatização, contribuindo para o 
desmantelamento da educação pública e a desmobilização da luta dos servidores da educação por melhores salários e condições de trabalho.

\section{REFERÊNCIAS}

A FRONTEIRA. Íntegra do depoimento da professora Ivone Nieradka na Comissão do IDEB. 2013a. Disponível em: < http://www.afronteira.com/br/ noticias/cidade/integra-do-depoimento-da-professora-ivone-nieradka-na-ce-doideb>. Acesso em 24 ago. 2014.

A FRONTEIRA. As crianças foram treinadas sim, reforça a professora Marli. 2013b. Disponível em: < http://afronteira.com/br/noticias/cidade/ascricancas-foram-treinadas-sim-reforca-professora-marli>. Acesso em 25 mai. 2014.

A FRONTEIRA. Éramos forçados a passar alunos em ano de IDEB, revela professora Dinorá. 2013c. Disponível em: <http://www.afronteira.com/ $\mathrm{br} /$ noticias/cidade/eramos-forcados-a-passar-alunos-em-anos-do-ideb-dizprofessora>. Acesso em 20 ago. 2014.

ABREU. A. S. A arte de argumentar: gerenciando razão e emoção. $8^{a}$ ed. Cotia: Ateliê Editorial. 2005.

ARAÚJO, L. Os fios condutores do PDE são antigos. 2007. Jornal de Políticas Educacionais. v. 01, n. 02 set. 2007. p. 24-31. Disponível em:

$<$ http://ojs.c3sl.ufpr.br/ojs/index.php/jpe/article/view/15000>. Acesso em: 29 set. 2014.

BOURDIEU, P; PASSERON, J. C. A reprodução: elementos para uma teoria do sistema de ensino. Rio de Janeiro: Francisco Alves, 1975.

BRASIL. INEP - O que é IDEB. 2011. Disponível em:

$<$ http://portal.inep.gov.br/web/portal-ideb/o-que-e-o-ideb>. Acesso em: 12 jul. 2014.

BRASIL. INEP - Resultados e Metas. 2012a. Disponível em:

<http://ideb.inep.gov.br/resultado/home.seam?cid=256111>. Acesso em: 29 mai. 2014.

BRASIL. INEP - Resultados e Metas. 2012b. Disponível em: 
$<$ http://ideb.inep.gov.br/resultado/home.seam?cid=256111>. Acesso em:28 set. 2014.

CAMARGO, R. B.; PINTO, J.M.R.; GUIMARÃES, J. L. e Sobre o Financiamento no Plano de Desenvolvimento da Educação. Cadernos de pesquisa, v. 38, n. 135, p. 817-839, set/dez. 2008. Disponível em: <http://www.scielo.br/pdf/cp/ v38n135/v38n135a14.pdf> Acesso em 15 fev. 2015.

CHAVES, N.M.D. Meritocracia: Revelando as melhores pessoas ou o melhor das pessoas? Um Estudo de Caso em uma empresa brasileira. 2012. 119 p. Dissertação (Mestrado em Administração Profissional) - Fundação Pedro Leopoldo, Pedro Leopoldo-MG:. 2012. 119 p. Disponível em: <http://www. fpl.edu.br/2013/media/pdfs/mestrado/dissertacoes_2012/dissertacao_neuza_ maria_dias_chaves_2012.pdf> Acesso em 24 fev. 2015.

FERNANDES, R. O mentor da equação; entrevista a Marta Avancini. Revista Educação, São Paulo, edição 123, 2007. Disponível em: < http:/ / revistaeducacao. uol.com.br/textos/123/artigo234206-1.asp>acesso em: 28 set. 2014.

FOZ DO IGUAÇU. Secretaria Municipal da Educação. Divisão de Documentação e Legislação Escolar. Estatística do Resultado Final. Foz do Iguaçu: SMED, 2011.

FOZ DO IGUAÇU. Decreto $\mathbf{n}^{\circ} \mathbf{2 1 . 4 0 4}$, de 22 de junho de 2012. Regulamenta no âmbito da Secretaria Municipal da Educação o Acordo Metas do Programa Gestão Para Resultados, a serem atingidas e a forma de pagamento do Prêmio por Desempenho. Disponível em:<http://www.leismunicipais.com.br/cgi-local/ showinglaw.pl>. Acesso em: 07 jul.2014.

FREITAS, L.C. Eliminação adiada: o ocaso das classes populares no interior das escolas e a ocultação da (má) qualidade do ensino. Educação e Sociedade, v.28, n.100, p. 965-987, out. 2007. Disponível em: <http://www.scielo.br/pdf/es/ v28n100/a1628100.pdf>. Acesso em: 03 abr. 2014.

GAZETA DO POVO. Caderno Educação: Escola de Foz tira melhor nota do IDEB - Jornal Gazeta do Povo. 15/08/2012. Disponível em:

<http://www.gazetadopovo.com.br/educacao/conteudo.phtml?id=1286676>. Acesso em: 9 jun. 2014.

LOPES, A.; NICOLAU, A. Psicologia. O caminho da psicologia.BehaviorismoJohn Watson (1878-1958).2013. Disponível em: <http://caminhodapsicologia. webnode.com.pt/behaviorismo-watson>. Acesso em: 15 jul. 2014. 


\section{O IGUASSU. Relatório do Presidente da Comissão Especial do IDEB na}

Câmara Municipal de Foz do Iguaçu. Edição 64.29 de maio a 13 de junho de 2013. Ano IV, Edição Regional. Editora G do Iguaçu. 2013.

RAVITCH, D. Vida e morte do grande sistema escolar americano: como os testes padronizados e o modelo de mercado ameaçam a educação. Tradução Marcelo Duarte. Porto Alegre: Sulina, 2011.

SILVIO BENITEZ é mestrando do Curso Sociedade Cultura e Fronteira da Universidade Estadual do Oeste do Paraná UNIOESTE, turma de 2014, bacharel em Administração pela Unioeste (1993) Licenciatura Plena no Curso de Formação de Professores do curso Técnico pelo Centro Federal de Educação Tecnológica CEFET (1997), pós-graduado em Administração, Orientação e Supervisão Educacional (2005) e Gestão Ambiental nos Municípios (2010) pela Universidade de Norte do Paraná UNOPAR, funcionário público municipal e professor no curso subseqüente de Técnico em Recursos Humanos, Contabilidade e Administração pela Secretaria Estadual da Educação do Paraná. E-mail: silviobenitez33@yahoo. com.br

SILVANA APARECIDA DE SOUZA possui graduação em Pedagogia pela Fafijan (1987), Mestrado em Educação pela UFPR (2000) e Doutorado em Educação pela USP (2008). É professora do Programa Interdisciplinar Sociedade, Cultura e Fronteiras na Universidade Estadual do Oeste do Paraná - Unioeste Campus de Foz do Iguaçu. Pesquisa as implicações da reestruturação produtiva do capital na educação púbica: toyotismo na educação (gestão da qualidade total aplicada à educação; trabalho voluntário e responsabilidade social da empresa na educação; empreendedorismo na educação), educação e trabalho e suas relações com a administração escolar, participação, gestão democrática, relações entre o público e o privado na educação. E-mail: sasouzaunioeste@hotmail.com 